\title{
Editorial
}

\section{Commission's Work at the Crossroads of the COVID-19 Crisis, Policy Initiatives and Legislative Reviews}

We are living in extraordinary times; this is reflected in the State aid support measures adopted for mitigating the economic and financial consequences for undertakings due to the COVID-19 outbreak. The figures speak for themselves. Between March and December of 2020, while State aids of $€ 2.96$ trillion have been approved by the European Commission, around $€_{544}$ billion was actually spent by the Member States. This represents around 3.9\% of the EU GDP. In this context, the Commission has assessed a very large array of measures in record time. By April 2021, the Commission has adopted 515 decisions approving 631 national measures notified by all the Member States within the context of the COVID-19 outbreak. In parallel, the Commission has worked together with the Member States to put into place a relevant legal framework to use the full flexibility of the State aid rules to support the severe economic impact at this difficult time of the COVID-19 crisis. To remain appropriate, this Temporary Framework needed to be adapted to the economic and financial development of the crisis and its impact on the economic operators. Therefore, the Commission has regularly reviewed the Temporary Framework. By January 2021, the Commission had amended the rules in place for the fifth time by increasing the ceilings and allowing the conversion of certain repayable instruments into direct grants.

There is still a long way to go. Temporary provisions must be temporary. The post-COVID period needs to be prepared, with new, appropriate rules which accompany the phase out and prepare for recovery. It is in this context that the Commission is providing State aid guidance in support of the Recovery and Resilience Facility with the stated objective that Member States will invest in key priorities and flagship areas by using a budget of $€ 672.5$ billion. As for the review of the State aid legal framework, a few legislative projects are in preparation, such as the amendment of the GBER in the light of Invest EU and the adoption of a new Regulation on Foreign Subsidies by 2021.

Moreover, the existing State aid rules have been evaluated. The conclusion of this exercise was that the State aid rules are broadly fit for purpose. However, individual rules would need some adjustments and revisions. In addition, the Commission's priorities need to be implemented. In particular, the Green Deal and the EU's Industrial and Digital Strategies should be reflected in the new State aid rules. Designing the legal framework on State aid to contribute to this twin transition towards a green and digital economy presents an opportunity, but also a challenge. To this end, the Commission has launched the review of a large set of soft laws, such as the Broadband Guidelines, the RDI Framework, the Environmental and Energy State Aid Guidelines, the Communication on Important projects of Common European Interest or the Regional Guidelines. In the same vein, it is foreseen that a second targeted review of the GBER will take place in the light of the Green Deal. In a later phase, the rest of the State aid 
rule book will need to be looked at.

The programme is tight and ambitious. Nevertheless, this far-reaching work in progress, while complex, is necessary to support the Member States to get through the crisis and to put in place growth-promoting policies and steer economies towards the twin transition, while maintaining a level playing field. State aid control is a key tool to contribute the single market fit for this new age. After all, it is by regulating the present that we design the future.

* Dr Claire Micheau is Policy Coordinator at the European Commission (DG Competition). Any opinions expressed by the author are personal and do not reflect the views of any institution. 